\title{
Complete heart block associated with device closure of perimembranous ventricular septal defects
}

\author{
Dragos Predescu, MD, Rajiv R. Chaturvedi, MD, PhD, Mark K. Friedberg, MD, Lee N. Benson, MD, Akira Ozawa, MD, and \\ Kyong-Jin Lee, MD
}

From the Cardiac Diagnostic and Interventional Unit, the Labatt Family Heart Centre, the Hospital for Sick Children, the University of Toronto School of Medicine, Toronto, Ontario, Canada.

Received for publication Nov 24, 2007; revisions received Jan 31, 2008; accepted for publication Feb 19, 2008.

Address for reprints: Kyong-Jin Lee, MD, the Hospital for Sick Children, 555 University Ave, Toronto, Ontario, Canada M5G 1X8 (E-mail: kyong-jin.lee@sickkids.ca).

J Thorac Cardiovasc Surg 2008;136:1223-8 $0022-5223 / \$ 34.00$

Copyright (C) 2008 by The American Association for Thoracic Surgery

doi:10.1016/j.jtcvs.2008.02.037
Objective: The development of the Amplatzer Membranous VSD Occluder (AGA Medical Corp, Plymouth, Minn) for closure of the perimembranous ventricular septal defect has ameliorated many of the technical difficulties of previous devices. Application of this new technology requires comparative evaluation with the current standard of surgical repair. We report our experience of complete heart block associated with device closure of a large perimembranous ventricular septal defect with unequivocal indications for intervention.

Methods: We performed a retrospective review of 20 patients between January 2003 and August 2005 who underwent perimembranous ventricular septal defect device closure, 18 with hemodynamically large shunts meeting the surgical criteria for intervention. The median age was 1.6 years (range, $0.5-16.2$ years), and the median weight was $9.7 \mathrm{~kg}$ (range, $6.2-43 \mathrm{~kg}$ ).

Results: Acute complete shunt occlusion was achieved in all patients. There were no acute procedural complications. The median follow-up time was 23.1 months (range, 1-37.8 months). Four (22\%) had complete heart block at 17 days, 4.2 months, 8.8 months, and 37.5 months after implantation, respectively. No risk factors were identified for development of complete heart block, including age, weight, trisomy 21 , preceding conduction abnormalities, perimembranous ventricular septal defect size related to body surface area or device size, and progressive device flattening.

Conclusions: Device closure of large perimembranous ventricular septal defects in infants and children with the Amplatzer Membranous VSD Occluder resulted in excellent closure rates but an unacceptably high rate of complete heart block.

$\mathrm{P}$ erimembranous ventricular septal defects (PMVSDs) in infants and young children are the most common cause of a hemodynamically significant ventricular septal defect (VSD). Although device closure of certain VSDs (muscular, residual postsurgical, posttraumatic, and postinfarction defects) is highly effective, either by means of percutaneous catheterization or collaborative hybrid-type approaches, ${ }^{1-4}$ initial attempts at transcatheter PMVSDs were largely unsuccessful. ${ }^{5,6}$

The development of the Amplatzer Membranous VSD Occluder (AGA Medical Corp, Plymouth, Minn) has led to numerous case series, and more than 2000 devices have been implanted worldwide. ${ }^{7-13}$ Short- and medium-term follow-up indicates that many of the shortcomings of previous devices have been overcome, especially with respect to technical feasibility, shunt occlusion, and valvular dysfunction. However, there has been considerable uncertainty about the clinical importance of some of the occluded VSDs and also the long-term follow-up of these patients. ${ }^{10}$ This new technology requires comparison with the standard practice of surgical repair.

After this preliminary experience, our institution embarked on an evaluation of device closure of the PMVSD with unequivocal indications for intervention in patients who would have otherwise undergone surgical closure. Reports of device-associated complete heart block $(\mathrm{CHB})$ have emerged. ${ }^{13-17}$ 

Abbreviations and Acronyms
$\mathrm{CHB}=$ complete heart block
PMVSD $=$ perimembranous ventricular septal defect
PPM = permanent pacemaker
RBBB = right bundle branch block
VSD $=$ ventricular septal defect

We report on our experience of $\mathrm{CHB}$ associated with device closure of the hemodynamically significant PMVSD.

\section{Materials and Methods}

Review of the cardiac database identified all patients who underwent PMVSD device closure with the Amplatzer Membranous VSD Occluder. Clinical records, angiograms, electrocardiograms, and echocardiograms were reviewed. The study was approved by the Research Ethics Board at the Hospital for Sick Children.

\section{Patient Population}

Patients were eligible for device closure if 1 or more of the following indications were present: pulmonary-to-systemic blood flow (Qp/ Qs) ratio of greater than 1.5, heart failure not controlled with medications, evidence of left heart volume loading, and a history of previous endocarditis. Exclusion criteria included weight of less than 6 $\mathrm{kg}$, inlet extension of the PMVSD, pulmonary vascular resistance index of greater than $7 \mathrm{WU} / \mathrm{m}^{2}$ that was unresponsive to oxygen, additional lesions requiring surgical intervention (right/left ventricular outflow tract obstruction and aortic regurgitation), and parental preference for surgical intervention. For the purpose of this report, we focus on patients with either a large shunt (Qp/Qs ratio of $\geq 2$ or with pulmonary hypertension in the presence of a $\mathrm{Qp} / \mathrm{Qs}$ ratio of $<2$ ). Pulmonary hypertension was defined as a mean pulmonary artery pressure of $20 \mathrm{~mm} \mathrm{Hg}$ or greater based on the original natural history studies. ${ }^{18}$

\section{VSD Sizing and Device Implantation}

PMVSD anatomy and initial sizing were determined by means of transthoracic echocardiography. The parasternal short-axis and apical 4-chamber views were used to measure the short- and long-axis diameters, respectively, of the defect. Where the VSD was restrictive, size was based on the smallest jet width by means of color imaging. Baseline valvular regurgitation, aortic cusp prolapse, and the pressure gradient across the VSD were assessed.

All PMVSDs were closed with the Amplatzer Membranous VSD Occluder. Cardiac catheterization was performed after achievement of general anesthesia. Right and left heart hemodynamic assessments were performed. Device implantation followed the recommended protocol. ${ }^{7,8,11}$ Briefly, the PMVSD was crossed with a wire from the left ventricular side, the wire was snared in the pulmonary artery and exteriorized to the femoral vein to form an arteriovenous circuit, and the device was implanted through a long sheath traversing the PMVSD from the right to the left ventricle. Transesophageal echocardiography was used to assist in assessment of defect size and device position and to exclude device distortion of surrounding cardiac structures. The device was generally selected to be 1 to $2 \mathrm{~mm}$ larger than the VSD, as assessed by the combination of echocardiography and left ventricular angiography. Given that the device is circular in shape and the PMVSD more elliptical, the larger of the short- and long-axis defect diameters was used. The Amplatzer Membranous VSD Occluder was available in 2-mm increments at the time of this study.

\section{Follow-up}

All patients were monitored in the hospital for 24 hours after device implantation, and chest radiography, electrocardiography, and echocardiography were performed before discharge. Outpatient followup was with an electrocardiogram and echocardiogram at 1 week, 1 month, 6 months, 1 year, and then yearly.

Follow-up echocardiograms were reviewed to assess residual shunt and valvular regurgitation. We found attempts to measure disk diameter by means of echocardiography unreliable and therefore documented our subjective impression of whether the device had flattened over time.

\section{Statistical Analysis}

Descriptive statistics are reported as medians and ranges. The numeric variables for the 18 patients with hemodynamically significant PMVSDs were split into CHB and non-CHB groups and compared with the Mann-Whitney test. The Fisher test was used to compare categorical variables between the groups. All data analysis was performed in $\mathrm{R} 2.5 .1{ }^{19}$

\section{Results}

Between January 2003 and August 2005, 20 patients (12 male patients) underwent PMVSD device implantation. Patient demographics and clinical and hemodynamic data are summarized in Table 1. The median age was 1.6 years (range, $0.5-16.2$ years), and the median weight was $9.7 \mathrm{~kg}$ (range, $6.2-43 \mathrm{~kg}$ ). Eighteen patients met unequivocal criteria for VSD intervention (Qp/Qs ratio of $\geq 2[\mathrm{n}=10]$ or mean pulmonary artery pressure of $\geq 20 \mathrm{~mm} \mathrm{Hg}$ with a Qp/Qs ratio of $<2: 1[\mathrm{n}=8]$ ]). Patient 12 had left ventricular noncompaction with restrictive cardiomyopathy and high pulmonary artery pressures. Defects that did not meet the criteria of a large shunt were in patient 19 , who was referred for closure after a documented episode of infective endocarditis, and patient 20, who was a 7-year-old who was asymptomatic, taking no medication, and who had a cardiac nuclear angiogram that was difficult to interpret and reported a Qp/Qs ratio of between 1.5:1 and 3:1. Echocardiographic analysis demonstrated a gradient of $103 \mathrm{~mm} \mathrm{Hg}$ across the VSD, a left ventricular end-diastolic dimension $z$ score of +2.7 , and a left atrial diameter $z$ score of +1.9 . At catheterization, the $\mathrm{Qp} /$ Qs ratio was 1.8:1, and the mean pulmonary artery pressure was $15 \mathrm{~mm} \mathrm{Hg}$. There was a strong preference for closure by the referring cardiologist and the parents.

During this time period, 25 patients weighing $6 \mathrm{~kg}$ or more underwent surgical intervention with a PMVSD as the primary indication for the operation. Those with the secondary diagnoses of atrial septal defect, patent ductus arteriosus, and patent foramen ovale were included. Of this group, $13(52 \%)$ 
TABLE 1. Patient characteristics and hemodynamic and procedural data

\begin{tabular}{|c|c|c|c|c|c|c|c|c|c|c|}
\hline $\begin{array}{c}\text { Patient } \\
\text { no. }\end{array}$ & Age (y) & $\begin{array}{l}\text { Weight } \\
\text { (kg) }\end{array}$ & $\begin{array}{l}\text { Op/0s } \\
\text { ratio }\end{array}$ & $\begin{array}{l}\text { VSD size } \\
(\mathbf{m m})\end{array}$ & $\begin{array}{c}\text { VSD pressure } \\
\text { gradient }(\mathrm{mm} \mathrm{Hg})\end{array}$ & $\begin{array}{c}\text { PAPm } \\
\text { (mm Hg) }\end{array}$ & $\begin{array}{l}\text { Device size } \\
\text { (mm) }\end{array}$ & $\begin{array}{l}\text { Follow-up } \\
\text { (mo) }\end{array}$ & $\begin{array}{c}\text { Trisomy } \\
21\end{array}$ & CHB \\
\hline 1 & 0.9 & 8.1 & 1.6 & 12 & 42 & 49 & 14 & 26.1 & + & + \\
\hline 2 & 1.2 & 8.2 & 2.3 & 7 & 64 & 26 & 8 & 37.8 & + & + \\
\hline 3 & 1.3 & 9.9 & 1.9 & 10 & 33 & 28 & 12 & 23.9 & - & + \\
\hline 4 & 1.5 & 10.3 & 1.4 & 10 & 8 & 55 & 12 & 5.6 & + & + \\
\hline 5 & 0.5 & 6.2 & 2.0 & 7 & 18 & 26 & 8 & 24.6 & + & - \\
\hline 6 & 0.7 & 6.8 & 2.4 & 9 & 8 & 35 & 12 & 21.3 & - & - \\
\hline 7 & 1.5 & 7.5 & 1.6 & 10 & 36 & 55 & 12 & 32.2 & - & - \\
\hline 8 & 1.2 & 7.9 & 2.0 & 6 & 35 & 19 & 8 & 20.2 & + & - \\
\hline 9 & 1.4 & 8.2 & 2.0 & 9 & 51 & 30 & 10 & 25.4 & - & - \\
\hline 10 & 0.8 & 8.4 & 3.4 & 14 & 35 & 56 & 14 & 19.9 & - & - \\
\hline 11 & 1.8 & 8.8 & 3.0 & 12 & 23 & 39 & 14 & 31.5 & - & - \\
\hline 12 & 1.6 & 9.4 & 1.0 & 11 & 14 & 57 & 14 & 17.1 & - & - \\
\hline 13 & 1.6 & 10.3 & 2.8 & 12 & 58 & 28 & 14 & 1 & - & - \\
\hline 14 & 2.1 & 12.2 & 1.5 & 10 & 66 & 24 & 12 & 11.9 & - & - \\
\hline 15 & 3.0 & 12.6 & 1.4 & 8 & 56 & 59 & 10 & 20.3 & + & - \\
\hline 16 & 8.4 & 26.6 & 2.3 & 8 & 74 & 16 & 10 & 36.3 & - & - \\
\hline 17 & 10.5 & 38.5 & 1.0 & 12 & 112 & 35 & 14 & 22.4 & - & - \\
\hline 18 & 16.2 & 43.0 & 3.0 & 17 & 67 & 27 & 18 & 34.1 & + & - \\
\hline $19^{*}$ & 5.4 & 19.1 & 1.0 & 6 & 77 & 17 & 6 & 15.9 & - & - \\
\hline $20^{*}$ & 7.2 & 28.8 & 1.8 & 6 & 103 & 15 & 8 & 28.5 & - & - \\
\hline Median (range) & $1.6(0.5-16.2)$ & $9.7(6.2-43)$ & $2.0(1-3.4)$ & $9.5(6-17)$ & $47(8-112)$ & $29(15-59)$ & $12(6-18)$ & $23.1(1-37.8)$ & & \\
\hline
\end{tabular}

$V S D$, Ventricular septal defect; $P A P m$, mean pulmonary artery pressure; $C H B$, complete heart block. *Excluded in analysis of hemodynamically significant perimembranous ventricular septal defects.

weighed $8 \mathrm{~kg}$ or more, $12(48 \%)$ weighed $10 \mathrm{~kg}$ or more, and only 1 weighed $16 \mathrm{~kg}$ or more, reflecting our institutional criteria for PMVSD intervention being predominantly in small patients with large shunts. None of these patients have had CHB.

A device was deployed successfully in the standard fashion in all cases. The median fluoroscopic time was 27 minutes (range, 13-50 minutes). Acute complete VSD shunt occlusion was achieved in all patients. There were no major procedural complications. In 4 children (patients 7, 10, 11, and 12) the initial device prolapsed through the defect and was replaced with the next size up ( $2 \mathrm{~mm}$ larger). In 2 children the device size was $3 \mathrm{~mm}$ greater than the VSD size. In patient 12 the initial 12-mm device prolapsed through the 11$\mathrm{mm}$ VSD, and a 14-mm device was successfully implanted. Patient 6 had a 9-mm VSD closed with a 12-mm device. This device looked bulky after delivery but could not be retrieved because of entanglement within the tricuspid valve. Initially, tricuspid valve regurgitation was moderate, but 13 months later, it was mild.

Follow-up time at the last clinical assessment or until heart transplantation or development of CHB was a median of 23.1 months (range, 1-37.8 months). One patient had only 1 month of follow-up (patient 13). There were no deaths or device embolization. Twelve patients had new or increased valvular regurgitation $(60 \%)$, none of more than a mild degree at last follow-up. One child had self-limiting hemolysis that did not require blood transfusion (patient 1). The patient with restrictive cardiomyopathy had disease progression and underwent successful transplantation 2.2 years after device implantation.

New conduction abnormalities were observed after device implantation in $16(80 \%)$ children, 7 of whom had pre-existing abnormalities. The new abnormalities were bifascicular block $(\mathrm{n}=1)$, incomplete right bundle branch block (RBBB; $n=2)$, complete RBBB $(n=3)$, and firstdegree heart block $(n=1)$. These were transient in 3 and permanent in $13(65 \%)$ patients. Four $(20 \%)$ patients had CHB presenting at 17 days, 4.2 months, 8.8 months, and 37.5 months, respectively, after implantation.

Patient 4 presented with 3 syncopal episodes, 2 of which were associated with seizures. High-grade second-degree heart block and periods of asystole up to 30 seconds were observed. Emergency treatment with an isoproterenol infusion and transvenous pacing was initiated. The parents declined a trial of corticosteroids, and the device was removed at the time of permanent pacemaker (PPM) implantation and sinus rhythm recovered 1 day later. In the other 3 patients, CHB was diagnosed during routine follow-up. Ventricular rates were 43,49 , and 50 beats/min. All patients had at least $1 \mathrm{Hol}-$ ter examination demonstrating continuous sinus rhythm before development of CHB. All patients underwent PPM implantation within 0 to 10 days of diagnosis. The device was left in situ in 3 patients with late-onset CHB, and all remain pacemaker dependent. 
TABLE 2. Comparison between non-CHB and CHB groups (n=18)

\begin{tabular}{|c|c|c|c|c|c|}
\hline \multirow[b]{2}{*}{ Age (y) } & \multicolumn{2}{|c|}{$\begin{array}{c}\text { Non-CHB } \\
\text { group }(n=14)\end{array}$} & \multicolumn{2}{|c|}{$\begin{array}{c}\text { CHB group } \\
(\mathrm{n}=4)\end{array}$} & \multirow{2}{*}{$\begin{array}{c}\begin{array}{c}\boldsymbol{P} \\
\text { value }\end{array} \\
.22\end{array}$} \\
\hline & 1.6 & $(0.5-16.2)$ & 1.3 & $(0.9-1.5)$ & \\
\hline Weight (kg) & 9.1 & $(6.2-43)$ & 9.1 & (8.1-10.3) & .79 \\
\hline Qp/Os ratio & 2 & $(1.0-3.4)$ & 1.8 & $(1.4-2.3)$ & .45 \\
\hline Mean PAP $(\mathrm{mm} \mathrm{Hg})$ & 33 & $(16-59)$ & 39 & $(26-55)$ & .91 \\
\hline VSD size $(\mathrm{mm})$ & 10 & $(6-17)$ & 9.5 & $(7-12)$ & .71 \\
\hline VSD/BSA & 22.1 & (8.2-27.5) & 20.7 & $(16.3-28)$ & .79 \\
\hline Device size (mm) & 12 & $(8-18)$ & 12 & (8-14) & .74 \\
\hline Device/VSD & 1.2 & $(1.0-1.3)$ & 1.2 & $(1.1-1.3)$ & .87 \\
\hline "New device"/device & 0.9 & $(0.7-1.1)$ & 0.9 & $(0.8-1.0)$ & .91 \\
\hline Trisomy 21 & 4 & & 3 & & .24 \\
\hline
\end{tabular}

Values are presented as medians (ranges). CHB, Complete heart block; $P A P$, pulmonary artery pressure; VSD, ventricular septal defect; $B S A$, body surface area; "New device"/device, device size by the new formula to used device ratio.

We sought to identify risk factors for CHB using a detailed review of the cases, including procedural details, echocardiograms, and angiograms. There was no discernible difference between the CHB and non-CHB groups (Table 2 ), irrespective of whether we examined only the 18 patients who met the hemodynamic criteria for intervention or the extended group of all 20 patients (data not shown). Electrocardiograms with or without Holter examination after implantation and before diagnosis of CHB were normal for 2 patients and in 1 patient indicated new RBBB. Patient 1 with trisomy 21 had baseline PR-interval prolongation and progressed to bifascicular block (24 hours), trifascicular block ( 2 weeks), and then CHB (4.2 months). In the other 3 patients, there was no warning of CHB. Neither of the 2 patients with a device $3 \mathrm{~mm}$ larger than the VSD size had CHB.

Immediately after implantation, the device disks did not appear fully flattened in $14(78 \%)$ patients and progressively flattened in 7 (50\%) patients. However, the 2 groups did not differ significantly with respect to initial or subsequent device shape ( $P=1.00$ and $P=.6$, respectively).

Concern that use of the largest diameter of the VSD might lead to device oversizing and CHB led the manufacturer (AGA Medical Corp) to recommend a new formula (square root of the product of the short- and long-axis diameters of the PMVSD) for device sizing based on an assumed elliptical shape. Retrospective application of this new formula in our series recommended smaller devices in $10(71 \%)$ of the patients without $\mathrm{CHB}$ and in $3(75 \%)$ of the patients with $\mathrm{CHB}$. The ratio of the new device to the used device did not differ between the 2 groups (Table 2). All 4 devices that dislodged and required larger sizes were in the nonCHB group. In 2 of the 4 instances of device dislodgement, a device that was the same size or smaller than that recom- mended by this new formula was actually initially implanted but subsequently required a larger implant.

\section{Discussion}

The development of the Amplatzer Membranous VSD Occluder and similar devices has ameliorated many of the technical difficulties and decreased distortion of the surrounding valve apparatus that occurred with previous devices. These advantages have lead to renewed interest in this technique. Initial experience from multiple institutions reported no mortality, high acute technical success ( $89 \%$ to $100 \%$ ), and high occlusion rates (84\% to $100 \%$ ) in the absence of any major concerns. ${ }^{7-13}$ Similar to others, we also achieved high technical success with $100 \%$ shunt occlusion and good acute outcomes. Longer-term follow-up in our institution unveiled a high frequency (22\%) of CHB. Concurrently, sporadic published reports of acute and late $\mathrm{CHB}$ emerged with a reported incidence of $1 \%$ to $5 \%{ }^{14-17}$ Based on these data, PMVSD device implantation was terminated at our institution. Most recently, Butera and colleagues ${ }^{13}$ report longerterm follow-up in 104 patients at a median of 38.5 months. The incidence of CHB was $8.7 \%$, and PPM was required in $6(5.7 \%)$ patients, 2 in the early phase and 4 during late follow-up.

Conduction system injury from mechanical trauma/compression by the delivery system or device causing acute intraprocedural $\mathrm{CHB}$ has a reasonable probability of early resolution. Chronic inflammation or fibrosis is more likely to be responsible for the late-onset type. ${ }^{15,20}$ Clearly, some cases of early CHB resolve spontaneously or with temporary pacing, corticosteroid and/or high-dose acetylsalicylic acid therapy, or device removal. ${ }^{10,16}$ Recovery of sinus rhythm after PPM implantation without device removal has also been reported. ${ }^{7,14}$ However, in early-onset CHB it is likely that the highest chance of sinus rhythm recovery is with device removal. ${ }^{13}$ Of most concern is the late onset, lack of predictive factors, and potentially life-threatening presentation of CHB. Hemodynamic instability, including syncope, has been the presenting event in 10 reported cases, including our patient with seizure. Others were discovered on routine scheduled follow-up. ${ }^{13-17} \mathrm{CHB}$ occurred as late as 37 months after device implantation in our series.

\section{Identifying Risk Factors for Device-associated CHB}

PMVSD anatomy. The simple anatomic classification of a VSD in the perimembranous region belies the wide variability of its shape. The common denominator of such defects is the fibrous continuity between the leaflets of the tricuspid and aortic valves, which form part of the defect's margins, with the conduction tissue coursing posteroinferiorly. ${ }^{21}$ This begs the question of whether one device shape fits all PMVSDs and more prudently whether such a device can avoid damaging the conduction tissue. 
Because of concern that inlet extension of the VSD might predispose to $\mathrm{CHB}$, these patients were specifically excluded in our series. ${ }^{16}$

Device sizing. VSD sizing is challenging because the complexity of PMVSD geometry cannot be captured by measuring 1 or 2 dimensions available by means of standard echocardiographic and angiographic imaging. Echocardiographic analysis can overestimate VSD diameter by $21 \% .^{22}$ Efforts to minimize possible oversizing include new recommendations for device sizing, accounting for the elliptical shape of the PMVSD. Retrospective application of this new device size formula failed to identify oversizing as a risk factor. There are no reports of prospective application of this new method of device size selection. Device oversizing was not a risk factor for $\mathrm{CHB}$ in the series by Butera and colleagues. $^{13}$

Progressive device flattening of an originally oversized device has been hypothesized as a mechanism for the development of CHB. However, this was not observed in the patients with CHB in other series ${ }^{14,15}$ and was not significantly different in the patients with and without CHB in our series.

Patient characteristics. It has been suggested that smaller infants might be at higher risk, but in the reported cases of $\mathrm{CHB}$, age ranged from 2.5 to 12 years, and weights ranged from 14 to $45 \mathrm{~kg}{ }^{13-16}$ Weight in our series was lower than that of other series, with the median weight for the entire cohort being $9.7 \mathrm{~kg}$, reflecting our criteria for VSD intervention. There was no significant difference in weight between the CHB and non-CHB groups. In fact, the smallest 2 patients, weighing 6.2 and $6.8 \mathrm{~kg}$, both with large shunts and pulmonary hypertension, did not have $\mathrm{CHB}$. The minimum weight at which device implantation can be considered remains to be determined.

PMVSD surgery. VSD management aims to avoid morbidity and prevent premature mortality from chronic heart failure and pulmonary hypertension. ${ }^{23,24}$ Excellent outcomes are expected for the timely diagnosed PMVSD. Surgical intervention for the isolated PMVSD in experienced centers has achieved this with minimal mortality $(0 \%$ at our institution since the year 2000, unpublished data) and a very low incidence of CHB $(0.7 \%$ to $1 \%){ }^{25,26}$ Tucker and associates ${ }^{26}$ report from the Pediatric Cardiac Care Consortium database an incidence of PPM implantation in $0.8 \%$ of 1739 patients who weighed more than $8 \mathrm{~kg}$ and were primarily operated on to repair PMVSDs (ie, comparable patients eligible for PMVSD device closure). In the contemporary era of 1315 patients, the PPM rate was $0.4 \%$, and hospital mortality was $0.2 \% .{ }^{26}$ Morbidity remains with requirement of cardiopulmonary bypass, sternotomy, and psychosocial effect and thus provides impetus for the search for alternative therapies. ${ }^{27,28}$ Until there are data to demonstrate that the incidence of CHB can be decreased by changes in patient selection or device modification, the potential benefits of reducing surgical inter- vention-associated morbidity is not superseded by the risk of sudden, potentially life-threatening, late-onset CHB. With this rationale, in these patients with hemodynamically significant PMVSDs (ie, those with an unequivocal indication for intervention), we believe that surgical closure remains the treatment of choice.

\section{Limitations}

This is a single-center experience with small patient numbers that is focused on the large PMVSDs that in our institution would otherwise have been referred for surgical intervention. Patient number was limited by the termination of this technique based on CHB incidence. It is not representative of the entire PMVSD device experience, which includes many older and larger patients and smaller defects. In the study by Butera and coleagues, ${ }^{13}$ median weight was $26.5 \mathrm{~kg}$, mean pulmonary artery pressure was $16 \pm 5 \mathrm{~mm} \mathrm{Hg}$, and $37 \%$ of patients were older than 10 years. In this regard controversy exists regarding the contemporary criteria for VSD intervention because many of the patients in this series would not have met the criteria for VSD intervention in our institution. ${ }^{27-30}$ Only one type of device was used, and it is conceivable that alternative designs might be more favorable.

\section{Conclusion}

We sought to close significant PMVSDs in infants and small children who would otherwise have required cardiac surgery. Device architecture and sizing to avoid the conduction tissue around the complex geometry of the PMVSD has significant limitations. Despite excellent results for closure, there was a high rate of $\mathrm{CHB}(22 \%)$. No risk factors for $\mathrm{CHB}$ were identified. The late and insidious nature of the onset of CHB is a critical caveat for device closure of these large defects. Long-term follow-up is essential in patients who have had these devices implanted.

\section{References}

1. Bacha EA, Cao QL, Galantowicz ME, Cheatham JP, Fleishman CE, Weinstein SW, et al. Multicenter experience with perventricular device closure of muscular ventricular septal defects. Pediatr Cardiol. 2005;26: 169-75.

2. Holzer R, Balzer D, Cao QL, Lock K, Hijazi ZM. Amplatzer Muscular Ventricular Septal Defect Investigators. Device closure of muscular ventricular septal defects using the Amplatzer muscular ventricular septal defect occluder: immediate and mid-term results of a U.S. registry. $J$ Am Coll Cardiol. 2004;43:1257-63.

3. Holzer R, Balzer D, Amin Z, Ruiz CE, Feinstein J, Bass J, et al. Transcatheter closure of postinfarction ventricular septal defects using the new Amplatzer muscular VSD occluder: results of a U.S. registry. Catheter Cardiovasc Interv. 2004;61:196-201.

4. Knauth AL, Lock JE, Perry SB, McElhinney DB, Gauvreau K, Landzberg MJ, et al. Transcatheter device closure of congenital and postoperative residual ventricular septal defects. Circulation. 2004; 110:501-7.

5. Rigby ML, Redington AN. Primary transcatheter umbrella closure of perimembranous ventricular septal defect. Br Heart J. 1994;72:368-71.

6. Sideris EB, Walsh KP, Haddad JL, Chen CR, Ren SG, Kulkarni H. Occlusion of congenital ventricular septal defects by the buttoned device. 
"Buttoned device" Clinical Trials International Register. Heart. 1997; 77:276-9.

7. Hijazi ZM, Hakim F, Haweleh A, Madani A, Tarawna W, Hiari A, et al. Catheter closure of perimembranous ventricular septal defects using the new Amplatzer membranous VSD occluder: initial clinical experience. Catheter Cardiovasc Interv. 2002;56:508-15.

8. Fu Y-C, Bass J, Amin Z, Radtke W, Cheatham JP, Hellenbrand WE, et al. Transcatheter closure of perimembranous ventricular septal defects using the new Amplatzer membranous VSD Occluder. $J$ Am Coll Cardiol. 2006;47:319-35.

9. Holzer R, de Giovanni J, Walsh KP, Tometzki A, Goh TH, Hakim F, et al. Transcatheter closure of perimembranous ventricular septal defects using the Amplatzer Membranous VSD Occluder: immediate and midterm results of an international registry. Catheter Cardiovasc Interv. 2006;68:620-8.

10. Masura J, Gao W, Gavora P, Sun K, Zhou AQ, Jian S, et al. Percutaneous closure of perimembranous ventricular septal defects with the eccentric Amplatzer device: multicenter follow-up study. Pediatr Cardiol. 2005; 26:216-9.

11. Pedra CA, Pedra SR, Esteves CA, Pontes SC Jr, Braga SL, Arrieta SR, et al. Percutaneous closure of perimembranous ventricular septal defects with the Amplatzer device: technical and morphological considerations. Catheter Cardiovasc Interv. 2004;61:403-10.

12. Pinto RJ, Dalvi BV, Sharma S. Transcatheter closure of perimembranous ventricular septal defects using Amplatzer Asymmetric Ventricular Septal Defect Occluder: preliminary experience with 18-month follow up. Catheter Cardiovasc Interv. 2006;68:145-52.

13. Butera G, Carminati M, Chessa M, Piazza L, Micheletti A, Negura DG, et al. Transcatheter closure of perimembranous ventricular septal defects-early and long-term results. J Am Coll Cardiol. 2007;50: 1189-95.

14. Walsh MA, Bialkowski J, Szkutnik M, Pawelec-Wojtalik M, Bobkowski W, Walsh KP. Atrioventricular block after transcatheter closure of perimembranous ventricular septal defects. Heart. 2006;92: 1295-7.

15. Butera G, Chessa M, Carminati M. Late complete atrioventricular block after percutaneous closure of a perimembranous ventricular septal defect. Catheter Cardiovasc Interv. 2006;67:938-41.

16. Yip WC, Zimmerman F, Hijazi ZM. Heart block and empirical therapy after transcatheter closure of perimembranous ventricular septal defect. Catheter Cardiovasc Interv. 2005;66:436-41.
17. Sullivan ID. Transcatheter closure of perimembranous ventricular septal defect: is the risk of heart block too high a price? Heart. 2007;93:284-6.

18. Weidman WH, Blount SG, DuShane JW, Gersony WM, Hayes CJ, Nadas AS. Clinical course in ventricular septal defect. Circulation. 1977;56:I56-69.

19. R Development Core Team. R: a language and environment for statistical computing. Vienna (Austria): R Foundation for Statistical Computing; 2007. Available at: http://www.R-project.org.

20. Kreutzer J, Ryan CA, Gauvreau K, Van Praagh R, Anderson JM, Jenkins KJ. Healing response to the Clamshell device for closure of intracardiac defects in humans. Catheter Cardiovasc Interv. 2001;54: $101-11$.

21. McCarthy KP, Ho SY, Anderson RH. Categorisation of ventricular septal defects: review of the perimembranous morphology. Images Paediatr Cardiol. 2000;3:24-40.

22. Johnson TB, Fyfe DA, Thompson RP, Kline CH, Swindle MM, Anderson RH. Echocardiographic and anatomic correlation of ventricular septal defect morphology in newborn Yucatan pigs. Am Heart $J$. 1993;125:1067-72.

23. Campbell M. Natural history of ventricular septal defect. Br Heart J. 1971;33:246-57.

24. Weidman WH, Blount SG, DuShane JW, Gersony WM, Hayes CJ, Nadas AS. Clinical course in ventricular septal defect. Circulation. 1977;56:I56-69.

25. Andersen HØ, de Leval MR, Tsang VT, Elliott MJ, Anderson RH, Cook AC. Is complete heart block after surgical closure of ventricular septum defects still an issue? Ann Thorac Surg. 2006;82:948-57.

26. Tucker EM, Pyles LA, Bass JL, Moller JH. Permanent pacemaker for atrioventricular conduction block after operative repair of perimembranous ventricular septal defect. J Am Coll Cardiol. 2007;50:1196-200.

27. Neumayer U, Stone S, Somerville J. Small ventricular septal defects in adults. Eur Heart J. 1998;19:1573-83.

28. Backer CL, Winters RC, Zales VR, Takami H, Muster AJ, Benson DW Jr, et al. Restrictive ventricular septal defect: how small is too small to close? Ann Thorac Surg. 1993;56:1014-8.

29. Gabriel HM, Heger M, Innerhofer P, Zehetgruber M, Mundigler G, Wimmer M, et al. Long-term outcome of patients with ventricular septal defect considered not to require surgical closure during childhood. $J \mathrm{Am}$ Coll Cardiol. 2002;39:1066-71.

30. Waldman JD. Why not close a small ventricular septal defect? Ann Thorac Surg. 1993;56:1011-2. 